\title{
Quantum Chemical Studies on Molecular Structures of Copper-Pyridine Complexes
}

\author{
K. P. SRIVASTAVA*, S. K. SRIVATAW, V. K. SINGH and GAURAV SINHA \\ Department of Chemistry, Ganga Singh College \\ Jai Prakash University, Chapra-841301, India \\ jpukpsrichem@rediffmail.com
}

Received 1 January 2013 / Accepted 14 February 2013

\begin{abstract}
The $\mathrm{Cu}$-pyridine and $\mathrm{Cu}$-(pyridine $)_{2}$ complexes were studied by quantum chemical calculations. Although pyridine provides both $\sigma$ - and $\pi$-bonding capabilities towards metal atoms and ions, the mono-ligand and di-ligand $\mathrm{Cu}$-pyridine complexes are determined to be $\sigma$ - structures. In the di-ligand complex, the two pyridine rings prefer the eclipsed to the staggered form. Due to an additional $\mathrm{Cu}-\mathrm{N} \sigma$-bond and stronger ligand $\pi$-electron donation, the di-ligand complex possesses a stronger metal ligand interaction than the mono-ligand complex. Upon ionization, the metal-ligand bonding in the di-ligand complex is more strongly enhanced compared to the mono-ligand complex.
\end{abstract}

Keywords: Copper, Pyridines, Quantum chemical calculations, Metal-ligand bonding

\section{Introduction}

Metal-ligand weak interactions are known to play a profound role in supramolecular chemistry, biochemistry, catalysis and environmental science ${ }^{1-6}$. In the last 20 years, supramolecular chemistry has been considered to be a rapid growing branch for developing new materials by assembling various molecular blocks and metal ions. Detailed investigation of the structures and formations of supramolecular systems becomes crucial to make these assemblies suitable for applications as functional materials ${ }^{7}$. Therefore, it can be imagined that metal-ligand interactions are present everywhere in our world and it is valuable to explore how such interactions affect the environment from a chemistry viewpoint.

Copper plays an important role in organisms as one of the so-called "essential" metals. The ubiquitous $\mathrm{Cu}$-organonitrogen complexes and their extensive applications have inspired much interest in the bonding, structures and properties of $\mathrm{Cu}$ and nitrogen containing molecules. This research paper presents a systematic quantum chemical study of the metalligand binding interaction in $\mathrm{Cu}$-pyridine complexes.

Pyridine (Figure 1), a six-membered cyclic aromatic molecule with $\sigma$ and $\pi$ binding capabilities through its nitrogen electron lone pair and $\pi$ system, respectively, has inspired considerable interests in its bonding with metals over the last ten years. A number of experimental and theoretical investigations have established that most metal-pyridine complexes 
are $\sigma$ complexes $^{8-11}$. The bonding of pyridine to copper surfaces has been described by both $\sigma$ and $\pi$ interactions $^{12}$. In fact, a recent $a b$ initio theoretical study by Edmonds and coworkers $^{13}$ suggests that the anionic [Co-pyridine] ${ }^{-}$and $\left.[\mathrm{Co} \text {-(pyridine })_{2}\right]^{-}$complexes are formed via $\pi$ bonding. Therefore, it would be interesting to determine the bonding interaction between pyridine and other transition metal atoms such as copper.

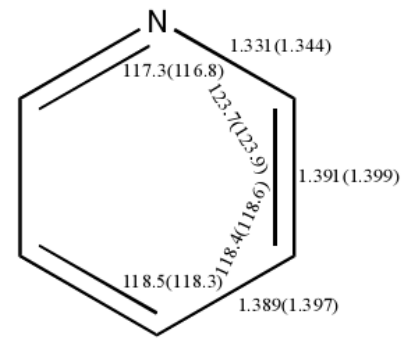

Figure 1. Structure of pyridine from B3P86/6-311+G(d,p) and MP2/6-311+G(d,p) method (in parenthesis: bond lengths, $\AA$, bond angles, ${ }^{0}$ )

\section{Quantum chemical calculations}

With a rapid growth in CPU speed, quantum chemical calculations using available program packages have become increasingly more sophisticated and valuable for predicting, modelling and understanding experimental measurements. Quantum chemical calculations can provide quite reliable results about molecular geometries, energies, electronic states, vibrational frequencies and reaction dynamics. In this research article, theoretical calculations were employed to predict the molecular structures, electronic states, bond strengths and vibrational frequencies of the neutral and ionic metal complexes as well as the AIEs (Adiabatic ionization energies) of the neutral metal complexes.

The Hartree-Fock (HF) method has been widely used to solve problems from small-to medium-sized molecules. However, as HF theory neglects electron correlation, it has been recognized that the HF method is not always reliable for describing many molecular systems. A number of so-called post-Hartree-Fock methods have been devised to improve theoretical results by including electron correlation to the multi-electron wave function. One of these approaches, Møller-Plesset (MP) perturbation theory, treats electron correlation as a perturbation of the HF function. In this theory, the energy of the system is expanded as:

$$
\mathrm{E}=\mathrm{E}_{0}+\lambda \mathrm{E}_{1}+\lambda^{2} \mathrm{E}_{2}+\ldots+\lambda^{\mathrm{n}} \mathrm{E}_{\mathrm{n}}
$$

Where, $E_{n}$ is the $n$th order corrections to the energy. In this research work, the second order MP method (MP2) was used in the theoretical calculations, as it yields good predictions for the $\mathrm{Cu}$-complexes. In addition to the MP2 method, the MP3 and MP4 methods include higher order energy corrections. However, the MP3 method yields little improvement and both MP3 and MP4 methods are much more expensive. Therefore, we mainly used the MP2 method for the theoretical calculations in this work. In this work, all the calculations were carried out with $6-311+\mathrm{G}(d, p)$ basis sets. The geometry optimization by the MP2 method was usually started from an optimized structure obtained from faster density functional theory (DFT) calculations. DFT methods are different from the wavefunction-based $a b$ initio methods where the energy of an electronic system is expressed in terms of its electron density. DFT methods have a lower computational cost and a wider range of applications. Although there have been some concerns about the accuracy and reliability of DFT, these calculations have becomevery popular in modelling various types of molecular systems ${ }^{14-16}$ and have yielded reasonable agreement with the experimental results. 


\section{Computational strategy and procedure}

In this work, both MP2 and DFT calculations were performed with the GAUSSIAN-2003 program package ${ }^{17}$. In the DFT calculations, Becke's three parameter hybrid exchange functional (B3) was combined with the gradient-corrected correlation functional of Perdew ${ }^{18}$ (P86) or Lee, Yang and Parr (LYP) ${ }^{19}$. Pople's triple zeta basis set with polarization and diffuse functions, 6-311+G( $d, p)$, was used in most calculations. Electron density maps were generated and vibrational modes were identified with GaussView ${ }^{20} 3.09$. AIEs were calculated to be the energy difference between the ionic and neutral complexes, where vibrational zero-point energy corrections were included. Metal-ligand bond dissociation energies were calculated to be the energy difference of the metal atoms and ligands from their complexes.

The theoretical calculations of metal complexes begin from geometry optimization of the free ligand. For ligands with several possible conformations, a systematic local minimum search needs to be performed starting from a number of initial guesses. The global minimum energy structure can be located by comparing the energies of all structures. During this search for the minimum energy structure, weak interactions, such as intramolecular hydrogen bonding, should be considered. Multidimensional FC factors were computed from the theoretical equilibrium geometries, harmonic frequencies and normal modes of the neutral and ionic complexes.

\section{Results and Discussion}

\section{Cu-pyridine Complex}

In our calculations of the Cu-pyridine complexes, $\sigma$ and $\pi$ structures were considered to be formed by $\mathrm{Cu}$ binding to the nitrogen atom and to the six-membered $\pi$ ring, respectively. However, no minimum energy $\pi$ structure was found for the neutral and ionic species. Table $1(\mathrm{a} \& \mathrm{~b})$ lists point groups, electronic states and energies, equilibrium geometries and vibrational frequencies of the Cu-pyridine $\sigma$ complexes from the B3P86 and MP2 calculations.

Table 1(a). Point groups, electronic states, equilibrium energies $\left(E_{e}\right.$, a.u.), geometries $\left(R, \AA{ }^{\circ},{ }^{0}\right)$ and vibrational frequencies $\left(\mathrm{cm}^{-1}\right)$ of the $\mathrm{Cu}$-pyridine $\sigma$ complexes from the B3P86 calculations using 6-311+G(d,p) basis set

\begin{tabular}{|c|c|}
\hline Method & B3P86 \\
\hline Point group & $\mathrm{C}_{2 \mathrm{v}}$ \\
\hline Electronic state & ${ }^{2} \mathrm{~A}_{1}$ \\
\hline nergies $\left(\mathrm{E}_{\mathrm{e}}\right.$, in a.u. $)$ & 1890.2 \\
\hline \multicolumn{2}{|l|}{ Geometries: } \\
\hline \multicolumn{2}{|c|}{$\mathrm{Cu}-\mathrm{N}=2.034, \mathrm{C}-\mathrm{N}=1.339, \mathrm{Cu}-\mathrm{N}-\mathrm{C}=120.9, \mathrm{~N}-\mathrm{C}-\mathrm{C}=122.7, \mathrm{C}-\mathrm{C}=1.386, \mathrm{C}-\mathrm{C}=1.389$} \\
\hline \multicolumn{2}{|l|}{$\mathrm{C}-\mathrm{C}-\mathrm{C}=118.8$} \\
\hline \multicolumn{2}{|l|}{ Frequencies: } \\
\hline \multicolumn{2}{|c|}{$\begin{array}{l}a_{1}: 3217,3195,3180,1654,1235,1051,1033,636,184 ; a_{2}: 1002,893,378 \\
b_{1}: 1017,960,758,709,419,41 ; b_{2}: 3211,3181,1631,1479,1375,1324,1174,1091,662,123 .\end{array}$} \\
\hline \multicolumn{2}{|c|}{$\begin{array}{l}\mathrm{b}_{1}: 1017,960,758,709,419,41 ; \mathrm{b}_{2}: 3211,3181,1631,1479,1375,1324,1174,1091,662,123 . \\
\text { Electronic state }\end{array}$} \\
\hline Equilibrium energies ( $E_{e}$, in a.u.) & 1890.001694 \\
\hline \multicolumn{2}{|l|}{ Geometries: } \\
\hline $\mathrm{Cu}-\mathrm{N}=1.904, \mathrm{C}-\mathrm{N}=1$ & $=1.389$ \\
\hline $\mathrm{Cu}-\mathrm{N}-\mathrm{C}=120.6, \mathrm{~N}-\mathrm{C}-\mathrm{C}=12$ & $\mathrm{C}-\mathrm{C}-\mathrm{C}$ \\
\hline \multicolumn{2}{|l|}{ Frequencies: } \\
\hline \multicolumn{2}{|c|}{$\begin{array}{l}a_{1}: 3232,3215,3308,1664,1520,1246,1102,1063,1046,667,271 ; a_{2}: 1004,891,392 ; \\
b_{1}: 1039,966,768,706,423,111 ; b_{2}: 3228,3212,1626,1488,1387,1324,1189,1106,658,168 .\end{array}$} \\
\hline
\end{tabular}


Table 1(b). Point groups, electronic states, equilibrium energies ( $E_{e}$, a.u.), geometries $\left(\mathrm{R}, \AA{ }^{\circ},{ }^{0}\right)$ and vibrational frequencies $\left(\mathrm{cm}^{-1}\right)$ of the $\mathrm{Cu}$-pyridine $\sigma$ complexes from the MP2 calculations using 6-311+G(d,p) basis set

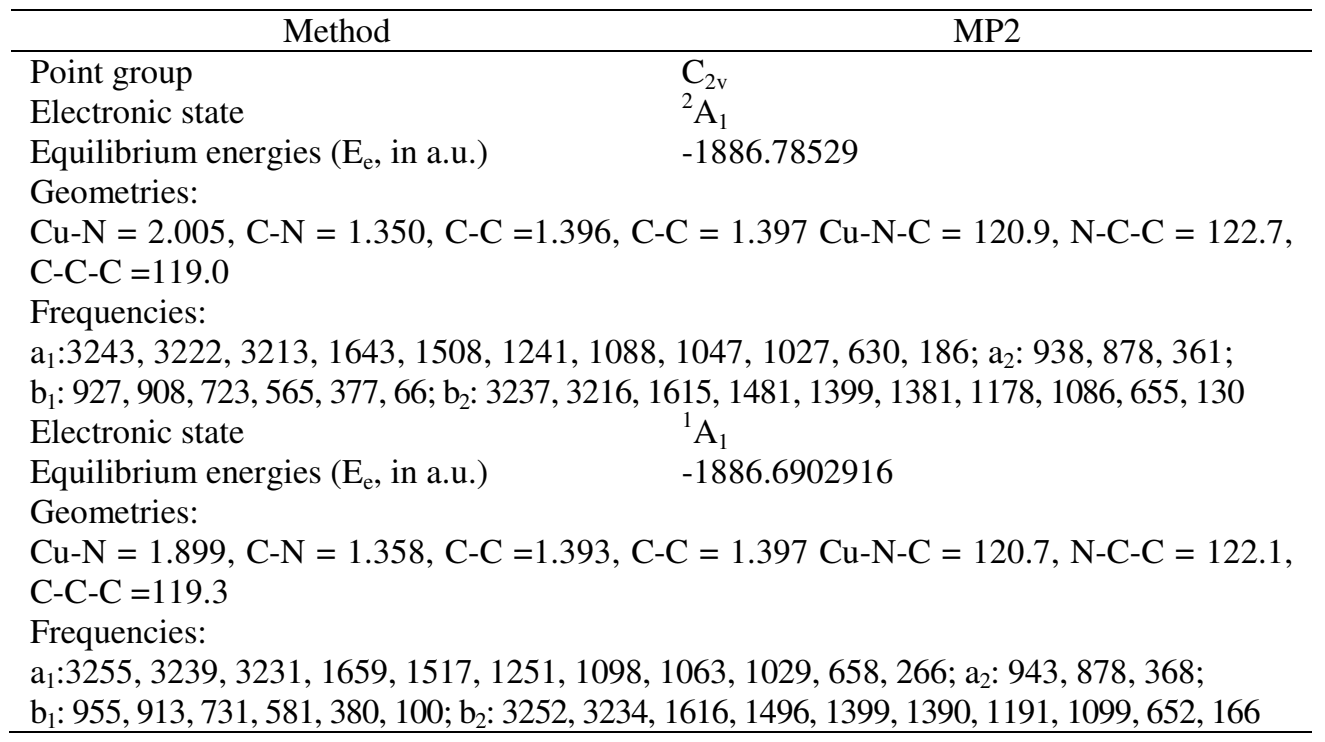

Both B3P86 and MP2 calculations predict a configuration in $\mathrm{C}_{2 \mathrm{v}}$ symmetry, where the $\mathrm{Cu}$ atom is coplanar to the six-membered $\pi$ ring. Both methods predict very little geometry change of the pyridine ring upon complexation. The $\mathrm{Cu}-\mathrm{N}$ distance is predicted to be $0.03 \AA$ longer by the B3P86 method than the MP2 method. Upon ionization, the $\mathrm{Cu}-\mathrm{N}$ distance is shortened due to reduced repulsion between the $\mathrm{Cu} 4 s^{1}$ and $\mathrm{N}$ lone-pair electrons and additional charge-dipole attraction. The B3P86 method predicts a slightly larger reduction $(\sim 0.13 \AA)$ of the $\mathrm{Cu}-\mathrm{N}$ distance than the MP2 method $(\sim 0.11 \AA)$.

\section{$\mathrm{Cu}$-(pyridine $)_{2}$ Complex}

The theoretical work of $\mathrm{Cu}$-(pyridine $)_{2}$ presented in this paper excludes the $\pi$ structure, because such a local minimum energy structure was not located for the Cu-pyridine complex. Therefore, the $\mathrm{Cu}$-(pyridine $)_{2}$ complex should be formed by $\mathrm{Cu}$ atom binding to the nitrogen of each pyridine molecule. The optimized point groups, electronic states, equilibrium energies and geometries and vibrational frequencies predicted by B3P86 and MP2 theories are listed in Table $2(\mathrm{a} \& \mathrm{~b})$.

According to the B3P86 calculations, the ground electronic states of the neutral and ionic $\mathrm{Cu}$-(pyridine $)_{2}$ complexes are ${ }^{2} \mathrm{~B}_{3 \mathrm{u}}$ and ${ }^{1} \mathrm{~A}_{\mathrm{g}}$ under $\mathrm{D}_{2 \mathrm{~h}}$ symmetry. The optimized $\mathrm{Cu}-\mathrm{N}$ distance in the $\mathrm{Cu}$-(pyridine) $)_{2}$ complex is much shorter than that in the $\mathrm{Cu}$-pyridine complex as seen in Table 3. Accordingly, the pyridine rings in $\mathrm{Cu}$-(pyridine $)_{2}$ undergo slightly larger geometry changes than the one in $\mathrm{Cu}$-pyridine upon complexation. Ionization of the ${ }^{2} \mathrm{~B}_{3 \mathrm{u}}$ state will generate the ${ }^{1} \mathrm{~A}_{\mathrm{g}}$ state, where the $\mathrm{Cu}-\mathrm{N}$ distance is slightly elongated and the pyridine rings have nearly the same geometry as that in free ligand. Thus, the metal-ligand bonds are largely enhanced by electron donation from the $\pi$ clouds of the ligands to the $\mathrm{Cu}$ $3 \mathrm{p}_{\pi}$ orbital. Such electron donation explains the shorter $\mathrm{Cu}-\mathrm{N}$ bond length in the neutral species compared to the ions. The $\mathrm{Cu}-\mathrm{N}$ bond lengths in the ion are slightly longer than those in the neutral complex due to the lack of $\pi$ electron donation. 
Table 2(a). Point groups, electronic states, equilibrium energies $\left(E_{e}\right.$, a.u.), geometries $\left(\mathrm{R}, \AA^{\circ},{ }^{0}\right)$ and vibrational frequencies $\left(\mathrm{cm}^{-1}\right)$ of the $\mathrm{Cu}$-(pyridine $)_{2}$ complexes from the B3P86 calculations using $6-311+\mathrm{G}(d, p)$ basis set

\begin{tabular}{ll}
\hline Method & B3P86 \\
\hline Point group & $\mathrm{D}_{2 \mathrm{~h}}$ \\
Electronic state & ${ }^{2} \mathrm{~B}_{3 \mathrm{u}}$ \\
Equilibrium energies $\left(\mathrm{E}_{\mathrm{e}}\right.$, in a.u.) & -2139.3650957
\end{tabular}

Geometries:

$\mathrm{Cu}-\mathrm{N}=1.860, \mathrm{C}-\mathrm{N}=1.369, \mathrm{C}-\mathrm{C}=1.373, \mathrm{C}-\mathrm{C}=1.402 \mathrm{~N}-\mathrm{Cu}-\mathrm{N}=180.0, \mathrm{Cu}-\mathrm{N}-\mathrm{C}=121.8$, $\mathrm{N}-\mathrm{C}-\mathrm{C}=123.1, \mathrm{C}-\mathrm{C}-\mathrm{C}=120.1, \mathrm{C}-\mathrm{N}-\mathrm{N}-\mathrm{C}=0.0$

Frequencies: $\mathrm{a}_{\mathrm{g}}: 3223,3206,3190,1668,1488,1234,1070,1051,1032,649,198 ; \mathrm{b}_{1 \mathrm{~g}}: 958,830,412$; $\mathrm{b}_{2 \mathrm{~g}}: 956,838,710,666,375,107 ; \mathrm{b}_{3 \mathrm{~g}}: 3209,3190,1523,1418,1362,1319,1133,1085$, 658,$147 ; \mathrm{a}_{\mathrm{u}}: 958,832,413,35 ; \mathrm{b}_{1 \mathrm{u}}: 3223,3206,3189,1609,1488,1212,1073,1049,987$, 665,$357 ; b_{2 u}: 3209,3190,1523,1416,1361,1323,1132,1089,659,250,39 ; b_{3 \mathrm{u}}: 956$, $837,711,667,395,168,34$

Electronic state

Equilibrium energies ( $E_{\mathrm{e}}$, in a.u.)

${ }^{1} \mathrm{~A}_{\mathrm{g}}$ $-2139.1975907$

Geometries:

$\mathrm{Cu}-\mathrm{N}=1.896, \mathrm{C}-\mathrm{N}=1.347, \mathrm{C}-\mathrm{C}=1.383, \mathrm{C}-\mathrm{C}=1.389 \mathrm{~N}-\mathrm{Cu}-\mathrm{N}=180.0, \mathrm{Cu}-\mathrm{N}-\mathrm{C}=120.8$, $\mathrm{N}-\mathrm{C}-\mathrm{C}=122.5, \mathrm{C}-\mathrm{C}-\mathrm{C}=119.0, \mathrm{C}-\mathrm{N}-\mathrm{N}-\mathrm{C}=0.0$

Frequencies:

$\mathrm{a}_{\mathrm{g}}: 3231,3213,3206,1668,1522,1247,1104,1067,1048,664,186 ; b_{1 \mathrm{~g}}: 1004,894,393$; $\mathrm{b}_{2 \mathrm{~g}}: 1034,965,770,709,426,108$; $\mathrm{b}_{3 \mathrm{~g}}: 3227,3209,1628,1485,1385,1323,1186,1102$, 661,$145 ; \mathrm{a}_{\mathrm{u}}: 1003,893,391,15 ; \mathrm{b}_{1 \mathrm{u}}: 3231,3213,3205,1668,1522,1244,1104,1069$, $1048,673,338 ; b_{2 u}: 3227,3209,1630,1487,1386,1325,1186,1105,661,237,40 ; b_{3 u}$ : 1034, 966, 772, 711, 439, 180, 35;

Point group

Electronic state

$\mathrm{D}_{2 \mathrm{~d}}$

Equilibrium energies ( $\mathrm{E}_{\mathrm{e}}$, in a.u.)

${ }^{1} \mathrm{~A}_{1}$

$-2139.1983542$

Geometries:

$\mathrm{Cu}-\mathrm{N}=1.896, \mathrm{C}-\mathrm{N}=1.347, \mathrm{C}-\mathrm{C}=1.383, \mathrm{C}-\mathrm{C}=1.389 \mathrm{~N}-\mathrm{Cu}-\mathrm{N}=180.0, \mathrm{Cu}-\mathrm{N}-\mathrm{C}=120.8$, $\mathrm{N}-\mathrm{C}-\mathrm{C}=122.4, \mathrm{C}-\mathrm{C}-\mathrm{C}=119.0, \mathrm{C}-\mathrm{N}-\mathrm{N}-\mathrm{C}=90.0$

Frequencies: $\mathrm{a}_{1}: 3231,3213,3206,1667,1522,1246,1104,1067,1047,664,187 ; \mathrm{a}_{2}: 1005,894,393$; $b_{1}: 1005,895,394,28 ; b_{2}: 3231,3213,3206,1667,1522,1244,1104,1069,1047,673$, 339; e: $3227,3209,1628,1486,1385,1323,1186,1103,1033,967,771,710,661,431$, 213, 121, 37;

Table 2(b). Point groups, electronic states, equilibrium energies ( $E_{e}$, a.u.), geometries $\left(\mathrm{R}, \AA{ }^{\circ},{ }^{0}\right)$ and vibrational frequencies $\left(\mathrm{cm}^{-1}\right)$ of the $\mathrm{Cu}$-(pyridine $)_{2}$ complexes from the MP2 calculations using 6-311+G(d,p) basis set

\begin{tabular}{ll}
\hline Method & MP2 \\
\hline Point group & $\mathrm{D}_{2 \mathrm{~h}}$ \\
Electronic state & ${ }^{2} \mathrm{~B}_{3 \mathrm{u}}$ \\
Equilibrium energies $\left(\mathrm{E}_{\mathrm{e}}\right.$, in a.u.) & -2134.483272 \\
Geometries: &
\end{tabular}


$\mathrm{Cu}-\mathrm{N}=1.838, \mathrm{C}-\mathrm{N}=1.358, \mathrm{C}-\mathrm{C}=1.355, \mathrm{C}-\mathrm{C}=1.393 \mathrm{~N}-\mathrm{Cu}-\mathrm{N}=180.0, \mathrm{Cu}-\mathrm{N}-\mathrm{C}=121.8$, $\mathrm{N}-\mathrm{C}-\mathrm{C}=123.2, \mathrm{C}-\mathrm{C}-\mathrm{C}=120.0, \mathrm{C}-\mathrm{N}-\mathrm{N}-\mathrm{C}=0.0$

Frequencies:

$\mathrm{a}_{\mathrm{g}}: 3262,3238,3217,1892,1548,1285,1161,1105,1060,667,209 ; \mathrm{b}_{1 \mathrm{~g}}: 1061,945,454$; $b_{2 \mathrm{~g}}: 1025,917,744,630,335,41 ; b_{3 \mathrm{~g}}: 3243,3215,1622,1446,1383,1268,1160,1111$, 687,$151 ; a_{\mathrm{u}}: 1063,947,458,-27 ; b_{1 \mathrm{u}}: 3264,3243,3216,2326,1550,1377,1247,1096$, $1052,689,374 ; b_{2 u}: 3243,3214,1624,1443,1385,1265,1163,1103,688,267,36 ; b_{3 u}$ : $1027,919,748,628,377,218,15$;

Electronic state

Equilibrium energies ( $E_{\mathrm{e}}$, in a.u.)

${ }^{1} \mathrm{~A}_{\mathrm{g}}$ $-2134.400602$

Geometries:

$\mathrm{Cu}-\mathrm{N}=1.862, \mathrm{C}-\mathrm{N}=1.357, \mathrm{C}-\mathrm{C}=1.393, \mathrm{C}-\mathrm{C}=1.397 \mathrm{~N}-\mathrm{Cu}-\mathrm{N}=180.0, \mathrm{Cu}-\mathrm{N}-\mathrm{C}=120.8$, $\mathrm{N}-\mathrm{C}-\mathrm{C}=122.2, \mathrm{C}-\mathrm{C}-\mathrm{C}=119.2, \mathrm{C}-\mathrm{N}-\mathrm{N}-\mathrm{C}=0.0$

Frequencies:

$\mathrm{a}_{\mathrm{g}}: 3255,3240,3230,1659,1517,1249,1103,1069,1032,661,195 ; \mathrm{b}_{1 \mathrm{~g}}: 940,879,367$; $b_{2 \mathrm{~g}}: 950,910,728,586,380,96 ; b_{3 \mathrm{~g}}: 3251,3237,1615,1493,1398,1386,1189,10961$, 653,$153 ; a_{\mathrm{u}}: 939,877,366,-21 ; b_{1 \mathrm{u}}: 3255,3240,3230,1660,1516,1247,1104,1071$, $1031,673,354 ; b_{2 u}: 3251,3236,1616,1494,1388,1189,1099,654,254,41 ; b_{3 u}: 950$, $911,729,583,395,178,34$;

Point group

Electronic state

Equilibrium energies ( $E_{e}$, in a.u.)

${ }^{2} \mathrm{~A}$

$-2134.5007558$

Geometries:

$\mathrm{Cu}-\mathrm{N}=1.863, \mathrm{C}-\mathrm{N}=1.355, \mathrm{C}-\mathrm{C}=1.394, \mathrm{C}-\mathrm{C}=1.397 \mathrm{~N}-\mathrm{Cu}-\mathrm{N}=180.0, \mathrm{Cu}-\mathrm{N}-\mathrm{C}=120.9$, $\mathrm{N}-\mathrm{C}-\mathrm{C}=122.4, \mathrm{C}-\mathrm{C}-\mathrm{C}=119.2, \mathrm{C}-\mathrm{N}-\mathrm{N}-\mathrm{C}=90.0$

Frequencies:

a: $3274,3253,3249,3240,3236,3233,3224,3208,1810,1653,1615,1606,1511,1487$, $1471,1393,1382,1378,1326,1258,1251,1245,1182,1123,1098,1093,1092,1068$, 1049, 1031, 993, 988, 968, 954, 945, 926, 883, 879, 846, 773, 731, 668, 667, 654, 650, $621,588,461,407,376,370,365,236,229,204,165,120,78,33,27,14$;

Electronic state

Equilibrium energies ( $\mathrm{E}_{\mathrm{e}}$, in a.u.)

${ }^{1} \mathrm{~A}_{1}$

Geometries:

$\mathrm{Cu}-\mathrm{N}=1.896, \mathrm{C}-\mathrm{N}=1.347, \mathrm{C}-\mathrm{C}=1.383, \mathrm{C}-\mathrm{C}=1.389 \mathrm{~N}-\mathrm{Cu}-\mathrm{N}=180.0, \mathrm{Cu}-\mathrm{N}-\mathrm{C}=120.8$, $\mathrm{N}-\mathrm{C}-\mathrm{C}=122.4, \mathrm{C}-\mathrm{C}-\mathrm{C}=119.0, \mathrm{C}-\mathrm{N}-\mathrm{N}-\mathrm{C}=90.0$

Frequencies: $\mathrm{a}_{1}$ : 3240, 3230, 1658, 1516, 1249, 1102, 1069, 1031, 662, 196; a $: 954,884,373 ; \mathrm{b}_{1}: 954$, $854,377,18 ; b_{2}$ : 3240, 3230, 1660, 1516, 1247, 1104, 1071, 1031, 674, 354; c: 3255,3251 , $3236,1615,1494,1399,1387,1189,1097,959,926,735,653,623,402,226,121,36$;

Table 3. Adiabatic ionization energies (AIE, $\left.\mathrm{cm}^{-1}\right)$, bond dissociation energies $\left(\mathrm{D}_{0}^{+} / \mathrm{D}_{0}\right.$ $\left.\mathrm{kJmol}^{-1}\right)$ and vibrational frequencies $\left(\mathrm{cm}^{-1}\right)$ of $\mathrm{Cu}$-pyridine and $\mathrm{Cu}$-(pyridine $)_{2}$ from the B3P86 and MP2 calculations using 6-311+G(d,p) basis set

\begin{tabular}{ccccc}
\hline Compounds & Parameters & Symbol & B3P86 & MP2 \\
\hline Cu-pyridine & AIE & & 48623 & 48623 \\
& $\mathrm{D}_{0}^{+} / \mathrm{D}_{0}$ & & $280.1 / 45.6$ & $258.7 / 47.4$ \\
& $\mathrm{Cu}^{+} / \mathrm{Cu}-\mathrm{L}$ stretch & $\mathrm{v}_{11}{ }^{+} / \mathrm{v}_{11}, \mathrm{a}_{1}$ & $271 / 183$ & $266 / 186$ \\
\hline
\end{tabular}




\begin{tabular}{ccccc}
\hline & $\mathrm{Cu}^{+}-\mathrm{L}$ o.p.bend & $\mathrm{v}_{20}{ }^{+} / \mathrm{v}_{20}, \mathrm{~b}_{1}$ & $111 / 41$ & $100 / 66$ \\
& Pyridine ring distortion & $\mathrm{v}_{10}{ }^{+}, \mathrm{a}_{1}$ & 667 & 658 \\
$\mathrm{Cu}$-(pyridine) ${ }_{2}$ & AIE & & 37713 & 17211 \\
& $\mathrm{D}_{0}^{+} / \mathrm{D}_{0}$ & $524.6 / 159.6$ & $517.3 / 23.5$ \\
& L-Cu-L symm.stretch & $\mathrm{v}_{11}{ }^{+}, \mathrm{a}_{\mathrm{g}}$ & 186 & 195 \\
& Pyridine ring distortion & $\mathrm{v}_{10}{ }^{+}, \mathrm{a}_{\mathrm{g}}$ & 664 & 658 \\
& Pyridine ring breath & $\mathrm{v}_{9}{ }^{+}, \mathrm{a}_{\mathrm{g}}$ & 1048 & 1032 \\
C-H i.p. bend & $\mathrm{v}_{7}{ }^{+}, \mathrm{a}_{\mathrm{g}}$ & 1104 & 1103 \\
& C-H i.p. bend & $\mathrm{v}_{6}{ }^{+}, \mathrm{a}_{\mathrm{g}}$ & 1247 & 1249 \\
& Pyridine rings distortion & $\mathrm{v}_{4}{ }^{+}, \mathrm{a}_{\mathrm{g}}$ & 1668 & 1659 \\
\hline
\end{tabular}

\section{Conclusion}

The $\mathrm{Cu}$-pyridine and $\mathrm{Cu}$-(pyridine) $)_{2}$ complexes were studied by quantum chemistry calculations. Although pyridine provides both $\sigma$ and $\pi$-bonding capabilities towards metal atoms and ions, the mono-ligand and di-ligand $\mathrm{Cu}$-pyridine complexes are determined to be $\sigma$ structures. In the di-ligand complex, the two pyridine rings prefer the eclipsed to the staggered form. Due to an additional $\mathrm{Cu}-\mathrm{N} \sigma$ bond and stronger ligand $\pi$ electron donation, the di-ligand complex possesses a stronger metal ligand interaction than the mono-ligand complex. Upon ionization, the metal-ligand bonding in the di-ligand complex is more strongly enhanced compared to the mono-ligand complex. Consequently, the ionization energy of the di-ligand complex is red shifted with respect to the mono-ligand complex.

\section{References}

1. Cowan J A. Chem Rev., 1998, 98(3), 1067-1088.

2. Hofmeier H and Schubert U S, Chem Soc Rev., 2004, 33, 373-399.

3. Gianneschi N C, Masar M S III and Mirkin C A, Acc Chem Res., 2005, 38(11), 825-837.

4. $\quad$ Sigel H and Sigel A, J Indian Chem Soc., 2000, 77, 501-509.

5. Yamamoto A, J Organomet Chem., 2000, 600(1-2), 159-167.

6. Sekhar K C, Chary N S, Kamala C T and Anjaneyulu Y, Proceedings of the Indian National Science Academy, Part B: Biological Sciences, 2004, 70, 13.

7. Skoda-Foeldes R and Kollar L, Chemical Reviews (Washington, DC), 2003, 103, 4095.

8. Hsu H C, Lin F W, Lai C C, Su P H and Yeh C S, New J Chem., 2002, 26, 481-484.

9. Guo W, Liu H and Yang S, Int J Mass Spectrom., 2003, 226(2), 291-304.

10. Wu D Y, Hayashi M, Chang C H, Liang K K and Lin S H, J Chem Phys., 2003, 118(9), 4073, DOI.ORG/10.1063/1.1541627.

11. Guo C, Cao Z and Zhang Q, Chem Phys Lett., 2004, 386(4-6), 448-453.

12. Lee J G, Ahner J, Yates J T, Jr, J Chem Phys., 2001, 114(19), 8722.

13. Douglas Edmonds B, Kandalam A K, Khanna S N, Li X, Grubisic A, Khanna I and Bowen K H, J Chem Phys., 2006, 124, 074316/1.

14. Balbuena P B and Seminario J M, Theoretical Computational Chem., 1995, 2, 383-401.

15. Barone V and Fliszar S, THEOCHEM, 1996, 369, 29-37

16. Bromley S T, French S A, Sokol A A, Sushko P V, Richard C and Catlow A, Recent Adv Computational Chem., 2002, 1, 45.

17. (a) Wong M W, Gonzalez C and Pople J A, GAUSSIAN 03, Revision C.02; Gaussian, Inc: Wallingford, CT, 2004; (b) Li S, Rothschopf G K, Fuller J F and Yang D S, J Chem Phys., 2003, 118, 8636.

18. Perdew J P, Phys Rev B, 1986, 33, 8822.

19. Lee C, Yang W and Parr R G, Phys Rev B, 1988, 37, 785 .

20. Roy Dennington II, John Millam T K, Ken Eppinnett, Lee Hovell W and Ray Gilliland, GaussView, Version 3.09; Semichem, Inc.: Shawnee Mission, KS, 2003. 